\title{
Malnutrition and anaemia among hospitalised children in Vavuniya
}

\author{
J Keerthiwansa, S Gajealan, S Sivaraja, K Y Subashini \\ (Index words: children, severe acute malnutrition, anaemia, iron deficiency, Vavuniya)
}

\begin{abstract}
We conducted a cross sectional descriptive study to describe the factors associated with the degree of malnutrition among hospitalised malnourished children in General Hospital, Vavuniya. All hospitalised children from January to June $2012(n=1210)$ were screened and the nutritional status assessed using WHO growth standards for weight for height/length. A total of 179 children with moderate acute malnutrition (MAM) (14.8\%) and 105 children with severe acute malnutrition (SAM) $(8.7 \%)$ were detected during this period. Having SAM (compared to MAM) was associated with lower maternal education $(p<0.001)$, lower paternal education $(p<0.001)$, low family income $(p=0.022)$ and mother being a housewife $(p=0.009)$. Prevalence of anaemia among 284 malnourished children was mild $32.4 \%(n=92)$, moderate $22.2 \% \quad(n=63)$ and severe $0.7 \%(n=2)$. Anaemia was highest among infants and prevalence decreased with increasing age. Social determinants played an important role in degree of malnutrition and anaemia among malnourished children admitted to the General Hospital, Vavuniya.
\end{abstract}

Ceylon Medical Journal 2014; 59: 141-143

\section{Introduction}

Sri Lanka is a developing country with good child health statistics [1]. Routine data from Sri Lanka shows that the infant mortality rate was 9.2 per 1000 live births and neonatal mortality rate was 6.8 per 1000 live births in 2012 [2]. While most of the child health statistics are improving in Sri Lanka, nutrition related problems are still a major public health problem. Prevalence of stunting, wasting and underweight among children less than five years of age in 2006 was $22.2 \%, 18 \%$ and $25.4 \%$ respectively [3]. Prevalence of anaemia among children under five years of age is 33\%. Among infants aged 9-11 months, the prevalence of anaemia is as high as $60.5 \%$ [3].

After 30 years of war, Northern Province of Sri Lanka is now slowly coming back to normal. The basic childcare services such as vaccination is reported to be similar to other areas of the country [4]. However, there is scarcity of data on the nutritional status of children in these areas and the objective of the present study was to describe the nutritional status and correlates of levels of malnutrition among hospitalised children in Vavuniya.

\section{Methods}

This was a descriptive cross sectional study carried out in the paediatrics ward of General Hospital, Vavuniya, which is the main hospital in the Vavuniya District. Study population included children aged 6 months to 5 years, admitted to the paediatric ward and having a weight for height/length less than 2SD of WHO growth standards [5]. Study was carried out from January to June 2012. On admission to the paediatric ward, all children were screened to select eligible participants to the study. Weight and height/length measurements were done using standard protocols for anthropometric measurements of children by three MBBS qualified medical officers trained in anthropometric measurement. Weight for height/length was evaluated using WHO growth standards for weight for height/length charts, separately for girls and boys. For this study, we defined all those children between -2SD and -3SD as having moderate acute malnutrition (MAM) and <-3SD as severe acute malnutrition (SAM). All consecutive children fulfilling the inclusion criteria were recruited after taking the informed consent from caregivers. Once they were recruited for the study a sample of venous blood was obtained by a trained nurse using standard venesection procedure. Haemoglobin assess-ment was done using methaemoglobin method. Cut off values for haemoglobin was based on WHO guide on anaemia, 2011 [6]. Chi-square statistics were used for statistical testing. Approval for this study was obtained from the Ethical Review Committee of the College of Paediatricians.

\section{Results}

A total of 1210 children were screened during the study period. Based on the WHO growth standards, 284 $(23.5 \%)$ children were either in MAM $(n=179,14.8 \%)$ or SAM $(n=105,8.7 \%)$ categories. Median age of the study sample of 284 malnourished children was 24 months (IQR $12-38)$. Majority of children were male $(n=164,57.7 \%)$ and belonged to Tamil ethnic group ( $\mathrm{n}=201,70.8 \%$ ) (Table 1). Comparison of MAM and SAM children showed that children who were having SAM belonged to a more

General Hospital, Vavuniya.

Correspondence: GWJK, e-mail: <janaki_kee@yahoo.com>. Received 17 May 2014 and revised version accepted 9 October 2014. Competing interests: none declared. 
socially deprived group (Table 2) compared to children having MAM. Age, sex and ethnicity were not associated with degree of malnutrition.

Table 1. Socio demographic characteristics of the study sample of 284 malnourished children

\begin{tabular}{lrr}
\hline \multicolumn{1}{l}{ Sex } & Number & Percentage \\
$\quad$ Male & 120 & 42.3 \\
$\quad$ Female & 164 & 57.7 \\
Age & & \\
$\quad<12$ months & 63 & 22.2 \\
12-36 months & 152 & 53.5 \\
37-54 months & 69 & 24.3 \\
Ethnicity & & \\
$\quad$ Tamil & 201 & 70.77 \\
$\quad$ Sinhalese & 67 & 23.59 \\
$\quad$ Moor/Malay & 16 & 5.63 \\
Average monthly income & & \\
$\quad<$ Rs.3000 & 35 & 12.4 \\
Rs.3000-5000 & 32 & 11.4 \\
Rs.5001-10,000 & 79 & 28.0 \\
Rs.10,001-25,000 & 97 & 34.4 \\
$\quad>$ Rs.25,000 & 39 & 13.8 \\
\hline
\end{tabular}

Table 2. Degree of malnutrition by socioeconomic characteristics

\begin{tabular}{|c|c|c|c|c|c|}
\hline \multirow[b]{2}{*}{ Characteristic } & \multicolumn{2}{|c|}{$\begin{array}{l}\text { Moderate } \\
\text { acute } \\
\text { malnutrition }\end{array}$} & \multicolumn{2}{|c|}{$\begin{array}{l}\text { Severe acute } \\
\text { malnutrition }\end{array}$} & \multirow[t]{2}{*}{ Significance } \\
\hline & $\mathrm{n}$ & $\%$ & $\mathrm{n}$ & $\%$ & \\
\hline \multicolumn{6}{|c|}{ Maternal education } \\
\hline $\mathrm{Up}$ to $\mathrm{O} / \mathrm{L}$ & 121 & 67.6 & 91 & 86.7 & $\begin{array}{l}\text { Chi-square }= \\
12.716\end{array}$ \\
\hline Beyond $\mathrm{O} / \mathrm{L}$ & 58 & 32.4 & 14 & 13.3 & $\mathrm{p}<0.001$ \\
\hline \multicolumn{6}{|c|}{ Paternal education } \\
\hline $\mathrm{Up}$ to $\mathrm{O} / \mathrm{L}$ & 101 & 56.4 & 81 & 77.1 & $\begin{array}{l}\text { Chi-square }= \\
12.342\end{array}$ \\
\hline Beyond $\mathrm{O} / \mathrm{L}$ & 78 & 43.6 & 24 & 22.9 & $\mathrm{p}<0.001$ \\
\hline \multicolumn{6}{|c|}{ Maternal occupation } \\
\hline Housewife & 121 & 67.6 & 86 & 81.9 & $\begin{array}{l}\text { Chi-square= } \\
6.855\end{array}$ \\
\hline Employed & 58 & 32.4 & 19 & 18.1 & $\mathrm{p}<0.009$ \\
\hline \multicolumn{6}{|l|}{ Family income } \\
\hline$\geq$ Rs. 25,000 & 31 & 17.3 & 8 & 7.6 & $\begin{array}{l}\text { Chi-square }= \\
5.256\end{array}$ \\
\hline$<$ Rs. 25,000 & 148 & 82.7 & 97 & 92.4 & $\mathrm{p}<0.022$ \\
\hline
\end{tabular}

Mean haemoglobin concentration among the study sample was $10.7 \mathrm{~g} / \mathrm{dl}$ (SD 1.13). Of the 284 malnourished children, 157 (55.5\%) had mean haemoglobin concentration less than $11 \mathrm{~g} / \mathrm{dl}$ and were classified as anaemic. Prevalence of mild, moderate and severe anaemia in the sample of malnourished children was $32.4 \%(n=92), 22.2 \%(n=63)$ and $0.7 \%(n=2)$ respectively. Among malnourished infants aged 6-12 months, the prevalence of anaemia was $68.3 \%(n=43)$, compared to $55.9 \%(\mathrm{n}=85)$ among malnourished children aged 1-3 years and $39.1 \%(\mathrm{n}=27)$ among malnourished children aged 3-5 years (Chi-square 12.34, $p=0.002$ ). Of the 77 malnourished children whose mothers were employed, 35 (45.5\%) were anaemic compared to $139(58.9 \%)$ among housewives (chi-square 4.127, $p=0.042$ ). Even though the proportion of anaemic children were higher among the parents who were less educated and having low income, those differences were not statistically significant. Of the anaemic children, $62(39.5 \%)$ had SAM compared to 42 (33.3\%) among non-anaemic. This difference was not statistically significant.

\section{Discussion}

This study shows that the prevalence of malnutrition among hospitalised children in Vavuniya Hospital was $23.5 \%$ in 2012. In 2006, Sri Lankan DHS was not carried out in Vavuniya district due to security reasons and malnutrition data are not available. However, of the 20 district surveyed, 9 had a prevalence of wasting more than $20 \%$ and five districts reported a value more than $23.5 \%$ in the general population. However these rates are from community samples and not hospitalised children [3]. Prevalence of anaemia among hospital visiting children in Colombo was reported as 52.6\% in 1992 (cut off value was $11.5 \mathrm{~g} / \mathrm{dl}$ ) [7]. In the present study, prevalence of anaemia among hospitalised children with malnutrition was $55.5 \%$, which is compatible with the previous hospital based study. Another major implication of this study is that the children with SAM were from more socially deprived groups. Targeted health promotional programmes may be needed in this area to improve health status of children in socially deprived communities.

One major limitation of this study is that this cannot be generalised to the children in Vavuniya District. This study could not identify the determinants of malnutrition because we did not compare with a healthy group of children. The clinical diagnosis of the children were also not included in this study therefore clinical causes of malnutrition could not be identified.

In conclusion, prevalence of MAM and SAM among hospitalised children in Vavuniya was similar to other parts of the country. More than half the malnourished children were anaemic. 


\section{References}

1. Senanayake H, Goonewardene M, Ranatunga A, Hattotuwa R, Amarasekera S, Amarasinghe I. Achieving Millennium Development Goals 4 and 5 in Sri Lanka. British Journal of Obstetrics and Gynaecology 2011; 118: 78-87.

2. http://www.familyhealth.gov.lk/web/index.php? option $=$ com_content\&view $=$ article $\&$ id $=134 \&$ Itemid $=$ 74\&lang=en\# accessed on 2nd March 2014.

3. Department of Census and Statistics. Sri Lanka Demographic and Health Survey 2006-07. Colombo: Ministry of Healthcare and Nutrition, 2009.

4. Parameswaran A, Wijesinghe PR. Was there a disparity in age appropriate infant immunization uptake in the theatre of war in the North of Sri Lanka at the height of the hostilities?: a cross-sectional study in resettled areas in the Kilinochchi district. BMC International Health and Human Rights 2012; 12: 26 .
5. WHO Multicentre Growth Reference Study Group. WHO child growth standards based on length/height, weight and age. Acta Paediatrica 2006; 450: 76-85.

6. World Health Organization. Haemoglobin concentrations for the diagnosis of anaemia and assessment of severity. Geneva: World Health Organization 2001.

7. de Silva A, Atukorala S, Weerasinghe I, Ahluwalia N. Iron supplementation improves iron status and reduces morbidity in children with or without upper respiratory tract infections: a randomized controlled study in Colombo, Sri Lanka. American Journal of Clinical Nutrition 2003; 77 : 234-41. 